\title{
Generation and Characterization of Humanized Mice Carrying COMTI58 Met/Val Alleles
}

\author{
Victoria Risbrough*, ${ }^{, 1,2}$, Baohu Ji', Richard Hauger ${ }^{1,2}$ and Xianjin Zhou*, ${ }^{*, 2}$ \\ 'Department of Psychiatry, University of California San Diego, La Jolla, CA, USA; ${ }^{2}$ Research Service, VA San Diego Healthcare System, \\ La Jolla, CA, USA
}

\begin{abstract}
The Vall58Met polymorphism of human catechol-o-methyltransferase (COMT) is one of the most well-studied single-nucleotide polymorphisms in neuropsychiatry; however, findings are inconsistent due to human genetic heterogeneity. We created the first 'humanized' COMTVal I58Met mouse lines, which carry either human COMT Val or Met alleles via gene targeting. The 'humanized' mouse model enables strict comparison of the physiological functions of the two alleles. Consistent with human observation, Met/Met mice exhibited a 30\% reduction in enzymatic activity compared with $\mathrm{Val} / \mathrm{Val}$ mice. On the basis of the reported differences in human Met and $\mathrm{Val}$ carriers across working memory, fear processes and sensorimotor gating, we examined these functions between sibling Met/Met and $\mathrm{Val} / \mathrm{Val}$ mice. $\mathrm{Val} / \mathrm{Val}$ mice exhibited robust reductions in spatial working memory compared with Met/Met mice in both sexes, with tolcapone treatment significantly reversing the Val/Val alternation deficits. Sex effects were observed in other behaviors, with male $\mathrm{Val} /$ Val mice exhibited lower prepulse inhibition compared with Met/Met mice, whereas female mice exhibited the opposite phenotype. Female but not male Met/Met mice exhibited reduced contextual fear, increased cued fear, and reduced extinction recall. Thus, these mice (I) support the argument that human COMT ValI58Met polymorphism modulates behavioral functions and most importantly (2) exhibit the expected treatment effects supporting the 'inverted $U$ shaped' dose response of catecholamine signaling on cognitive function. This model will be invaluable for understanding the effects of human COMT Val I 58Met polymorphism on cortical development and behavioral functions, and how this polymorphism modulates treatment response.

Neuropsychopharmacology (20I4) 39, I823-I832; doi:I0.I038/npp.20I4.29; published online 26 March 2014
\end{abstract}

\section{INTRODUCTION}

Catecholamines such as norepinephrine and dopamine are a class of chemical neurotransmitters that have central roles in the development of psychiatric disorders. The catechol-omethyltransferase (COMT) is one of the key enzymes in catecholamine clearance from the synapse. Human COMT mRNA is highly expressed in both prefrontal cortex and hippocampus, but has relatively low expression in striatum (Matsumoto et al, 2003). Two COMT allozymes, a longer membrane bound (-MB) and a shorter soluble (-S) COMT, are generated by differential use of translational start codon (Tunbridge et al, 2006). The membrane-bound MB-COMT, the predominant form in brain, is responsible for inactivation of dopamine on the surface of presynaptic and postsynaptic neurons (Chen et al, 2011b). Human COMT gene, localized on chromosome 22q11.2, is one of many genes deleted in 22q11.2 deletion syndrome patients who have highly increased risk for a broad spectrum of disorders, including schizophrenia, anxiety, mood

\footnotetext{
*Correspondence: Dr $\vee$ Risbrough and Dr X Zhou, Department of Psychiatry, University of California San Diego, 9500 Gilman Drive Mail Code 0804, La Jolla 92093-0804, CA, USA, Tel: + I 619543 3582, Fax: + I 619543 2493, E-mail: vrisbrough@ucsd.edu or xzhou@ucsd.edu Received I December 2013; revised I February 2014; accepted 3 February 20।4; accepted article preview online 10 February 2014
}

disorders, obsessive-compulsive disorder, and attentiondeficit disorder (Murphy et al, 1999a and b; Gothelf et al, 2005). These findings suggested human COMT as a plausible candidate gene for neuropsychiatric disorders.

A single-nucleotide polymorphism (SNP), causing a missense mutation of codon 158 Valine to Methionine, was found in human COMT gene (Lachman et al, 1996) with varying frequency across ethnic populations (Met allele varying from 0.1 to 0.62 ) (Palmatier et al. 1999). This COMT-Met polymorphism is unique for humans, and decreases COMT enzymatic activity $40 \%$ in prefrontal cortex tissue (Chen et al, 2004). A large number of human genetic association studies have been conducted to assess the association of COMT Val158Met with the risk of developing schizophrenia and other psychiatric disorders (Witte and Floel, 2012). Small increases in Val allele frequency have been reported in schizophrenia in some studies (Fan et al, 2005; Glatt et al, 2003), but in not others (Chen et al, 2011a; Nieratschker et al, 2010; Williams et al, 2005), while Met alleles are more frequent in some posttraumatic stress disorder (PTSD) populations (Boscarino et al, 2011; Kolassa et al, 2010; Valente et al, 2011). It is suggested that COMT predominantly affects dopamine metabolism in prefrontal cortex, where dopamine transporter expression is relatively low. Therefore, genetic association studies between COMT Met/Val and prefrontal cognitive functions were performed. Inconsistent results were reported for the association of the 
Met allele with either better ( Caldu et al, 2007; Egan et al, 2001) or worse (Buckert et al, 2012; Wang et al, 2013) cognitive performance. Considering enormous genetic heterogeneity of human population, it is not surprising to obtain contradictory results in the association studies.

The physiological functions of the mouse Comt gene have been studied using both knockout and transgenic approaches. Mouse Comt null mutants display significant increases in baseline dopamine levels in frontal cortex with no measurable changes in striatum (Gogos et al, 1998a), and significantly more L-DOPA loading, specifically in PFC, compared with wild-type mice (Huotari et al, 2002). Consistent with these findings, administration of tolcapone, a specific and brain-penetrant Comt inhibitor, significantly increases the level of extracellular dopamine in the rat medial prefrontal cortex (Tunbridge et al, 2004). These data support an important role for Comt in the turnover of dopamine in prefrontal cortex in rodents. Comt null mice also show subtle differences in cognitive functions including working memory, impulsive behavior and response to stress; however, it is not clear if (and what) compensatory changes have a role in these phenotypes. Studies on the human COMT Val allele were conducted using transgenic mice. Transgenic mice overexpressing COMT Val displayed deficient cognitive functions compared with Comt knockout mice (Papaleo et al, 2008a), suggesting that Comt efficacy has a role in cognition.

Despite extensive human genetic association studies and analyses of mouse Comt, it remains inconclusive whether human COMT Met and Val alleles have any differential physiological functions in vivo. Here, we report the generation of two mouse lines, via gene targeting, to carry either human COMT Met or Val allele. These two lines of humanized mice are genetically identical except for this one SNP. Our initial characterization of this line focused on phenotypes that have homologous measures in humans shown to be affected by COMT genotype, exploration, sensorimotor gating, fear learning/extinction, and working memory (see discussion for references). These behaviors are modulated by catecholamine signaling in the frontal cortex (for review see Swerdlow et al. 2001; Orsini and Maren, 2012; Lalonde, 2002), which is the suggested mechanism for Val158Met phenotype associations in humans. Here we report that humanized COMT Met/Met mice displayed better working memory than sibling COMT Val/Val mice and increased cued fear learning with reduced fear extinction. Significant sex effects were also observed in some but not all behaviors. These mice may be particularly useful for screening novel pharmacotherapeutics for enhancing catecholamine signaling in Val carriers, as well as dissecting the role of COMTVal158Met on brain development and function.

\section{MATERIALS AND METHODS}

\section{Generation of Humanized COMT Mouse Lines}

Human COMT Val cDNA was purchased from Open Biosystems (BC100018, in pCMV-SPORT6 Vector). Sitedirected mutagenesis was conducted to generate human COMT Met cDNA. A long (about $4.2 \mathrm{~kb}$ ) homology arm was amplified immediately upstream of exon 3 from mouse genomic DNA of $129 \mathrm{~S}$ embryonic stem (ES) cells. A short arm $(3 \mathrm{~kb})$ was amplified downstream of the mouse endogenous Comt coding sequence. The long arm was fused with human COMT Met and Val cDNA genes, respectively, which were further subcloned into the Sal I site of the targeting vector (Zhou et al, 1995). The short arm was cloned into the BamH I site. Two gene targeting constructs were generated for human COMT Met and Val alleles, respectively, and two lines were created, for more details see Supplementary Methods.

For behavioral studies, mice were backcrossed $N=7$ to a C57BL6J background, and then heterozygous COMT Met/ Val breeders were used to produce testable cohorts. Mice were tested for behavior between 2 and 6 months of age, with at least 2 weeks in-between tests in the following order: behavioral pattern monitor, prepulse inhibition (PPI), open field, light dark box, and fear conditioning. A second cohort was used to test spontaneous alternation.

\section{Southern Blot, Immunohistochemical Staining and Western Blot}

Southern blot hybridization was conducted as previously described (Zhou et al, 1995). Immunohistochemical staining of COMT was conducted as described previously (Kim et al, 2012). For details, see Supplementary Methods.

\section{COMT Activity Assay}

For this assay, frontal cortex of male 4-5 months old WT, $\mathrm{Val} / \mathrm{Val}$, Met/Met mice were used to detect COMT enzymatic activity as measured by a radioenzymatic assay (Tsao et al, 2012). For details see Supplementary Methods.

\section{Exploratory Behavior and Locomotor Activity}

Locomotor activity and investigatory behavior were measured under 'low stress' conditions (dark and enclosed) in behavioral pattern monitor chambers (BPM; San Diego Instruments, San Diego, CA; for detailed descriptions see Supplementary Methods and (Geyer et al, 1986; Risbrough et al, 2006a)). Total distance moved (cm), rears, and hole pokes were recorded for $60 \mathrm{~min}$ to assess horizontal, vertical, and exploratory activity, respectively. Exploratory behavior under mild stress conditions (open, brightly lit) was also assessed for $5 \mathrm{~min}$ using the Light-Dark Box and Open Field chambers, as previously described (Toth et al, 2014, see Supplementary Methods).

\section{PPI of Acoustic Startle}

PPI was characterized as described previously (Gresack and Risbrough, 2011). In brief, eight startle chambers (San Diego Instruments) were used to asses startle reactivity, habituation, and PPI. A $65 \mathrm{~dB}$ background was presented continuously. Acoustic startle pulses were $40 \mathrm{~ms}$ in duration, prepulses were $20 \mathrm{~ms}$ in duration. The acoustic startle session included five blocks. Sessions began with a 5 -min acclimation period followed by delivery of five each of $120 \mathrm{~dB}$ startle pulses. This block is used to allow startle to reach a stable level before specific testing blocks. Then a second block tested response threshold and included four each of five different acoustic stimulus intensities: 80, 90, 
100,110 , and $120 \mathrm{~dB}$ in a pseudorandom order. The third block consisted of 42 trials including 12 each of $120 \mathrm{~dB}$ startle pulse intensities and 10 each of three different prepulse trials $(68,71$, and $77 \mathrm{~dB}$ preceding a $120 \mathrm{~dB}$ pulse at a fixed interstimulus interval of $100 \mathrm{~ms}$ onset-onset). Alternating the intensity of the prepulse probes the effects of prepulse salience on PPI. The fourth block consisted of trials with the prepulse stimuli fixed at $77 \mathrm{~dB}$ intensity but varying in time presented before the onset of the pulse (25, $50,100,200$, and $500 \mathrm{~ms}$ onset-onset). Varied interstimulus intervals with a fixed, high prepulse intensity are the most common parameters used in human tests of PPI, as this approach probes the processing window in which the prepulse inhibits the startle response. The session ended with a fifth block of 5 pulses of $120 \mathrm{~dB}$. PPI was calculated as 100-[(response to "prepulse + pulse" trial/response to "pulse alone" trial) $\times 100$ ], with only the $120 \mathrm{~dB}$ pulse alone trials within a given block being used as the denominator. Habituation was assessed by the difference between startle responses to $120 \mathrm{~dB}$ during the first and the last sessions. In all experiments, the average startle magnitude over the record window (ie, $65 \mathrm{~ms}$ ) was used for all data analysis. The house light remained on throughout all testing sessions. The inter-trial intervals between stimulus presentations averaged $15 \mathrm{~s}$ (range of $7-23 \mathrm{~s}$ ).

\section{Working Memory Using T-Maze Spontaneous Alternation}

In humans, working memory has been shown to be associated with the Val158Met polymorphism (eg, Giacoumaki et al, 2008; Farrell et al, 2012). To test working memory, we used a common rodent test of spatial working memory that requires cortical catecholamine signaling (for review see Lalonde, 2002). This test takes advantage of a rodent's natural motivation to explore novel vs familiar environments. At each trial, the mouse is placed in the stem of the maze and allowed to choose one of two arms to explore. Typically mice and rats choose to explore arms that were not visited in the previous trial but instead alternate between arms. This task is considered a test of working memory as it requires the mouse to remember what arm was just recently visited, while disregarding all other previous visits (proactive interference). We conducted the spontaneous alternation test using a gray plastic T-maze as previously described (Bontempi et al, 2003). Mice were allowed $30 \mathrm{~s}$ in the start box before the start of each trial. After the start box period, the door was slid open and mice were allowed a free choice into either the left or right arm. After the mouse made a choice (all four paws in the chosen arm), the arm door was closed and the mice were allowed to explore the arm for $30 \mathrm{~s}$ before being removed and replaced in the start box for the next trial. A total of eight trials were completed (seven total possible alternations). \%Alternation was calculated as $100^{*}$ (number of alternations/7). Time to make a choice was also recorded. For further details of apparatus and testing procedure, see Supplementary Methods.

\section{Tolcapone}

One month later, female mice were re-tested for response to Tolcapone on spontaneous alternation using a within-subject design. Mice were injected with either vehicle (5\%Tween/ saline) or $20 \mathrm{mg} / \mathrm{kg}$ Tolcapone (gift from Dr T BallardYardy at Roche Pharmaceuticals) 30 min before testing via intraperitoneal injection. Behavioral testing was exactly as described above, with 1 week in-between tests, and dose order was counterbalanced across groups.

\section{Fear Conditioning and Extinction}

The procedure used in the fear conditioning experiment was adapted from previous studies (Gresack et al, 2010) using automated fear conditioning chambers (San Diego Instruments), for details on apparatus and freezing measurement, see Supplementary Methods). Day 1: after an 2-min acclimation period, mice were presented with a tone conditioned stimulus (CS: $75 \mathrm{~dB}, 4 \mathrm{kHz}$ ) for $20 \mathrm{~s}$ that co-terminated with a foot shock unconditioned stimulus (US: $1 \mathrm{~s}, 0.5 \mathrm{~mA}$ ). A total of three tone-shock pairings were presented with an inter-trial interval of $40 \mathrm{~s}$. To assess acquisition freezing was measured during shock presentations. Mice were replaced in their home cage $2 \mathrm{~min}$ after the final shock. We have found that these moderate shock parameters enable us to detect both increases and decreases in fear-conditioned behavior. Day 2: $24 \mathrm{~h}$ later, mice were re-exposed to the conditioning chamber to assess context-dependent fear retention. This test lasted $8 \mathrm{~min}$ during which time no shocks or tones were presented and freezing was scored for the duration of the session. Time freezing was blocked across 4, 2-min blocks. Day 3: $24 \mathrm{~h}$ after the context fear-retention test, mice were tested for CS-induced fear retention and extinction. The context of the chambers was altered across several dimensions (tactile, odor, visual) for this test in order to minimize generalization from the conditioning context. After a $2 \mathrm{~min}$ acclimation period, during which time no tones were presented ('pre-tone'), 32 tones were presented for $20 \mathrm{~s}$ with an inter-trial interval of $5 \mathrm{~s}$. Freezing was scored during each tone presentation and freezing was blocked into eight blocks of four tones. Baseline freezing during the acclimation period prior to the tone presentation was also assessed. Mice were returned to their home cage immediately after termination of the last tone. Day 4: after a 2 min acclimation period, during which time no tones were presented ('pre-tone'), short recall session of 12 tones was used to assess extinction recall. Tones were blocked into four blocks of four tones.

\section{Data Analysis}

We used standard multi-factorial ANOVA models with Gene and Sex as a between subject factor and time, block, prepulse/pulse parameters, and/or Tolcapone as within subject factors. Significant main effects or interactions were followed up by appropriate post hoc tests (Tukey's post hoc test or alpha-corrected paired $t$-tests for within-subject contrasts).

\section{RESULTS}

\section{Generation and Validation of Humanized COMT Val158Met Mice}

Mouse endogenous Comt gene consists of six exons with its start codon at the beginning of exon 3. To maximally 
preserve the $5^{\prime}$ end regulatory elements, we knocked-in human COMT Met and Val coding sequence to replace the entire mouse Comt coding sequence (Figure 1a). After homologous recombination, the knocked-in human COMT Met and Val alleles generated a new $3 \mathrm{~kb}$ BamH I band in addition to a $7 \mathrm{~kb}$ band of wild-type mouse Comt gene (Figure 1b). The human COMT Met and Val alleles successfully transmitted through germline. Breeding of the heterozygous COMT mice gave rise to expected segregation of wild-type, heterozygous, and homozygous mice (Figure 1c). All mice were healthy. Expression of human COMT Met and Val alleles were confirmed via sequencing after RT-PCR amplification (Figure 1d). To investigate whether the knocked-in human COMT Met and Val alleles display similar expression patterns to endogenous mouse Comt gene, we conducted immunohistochemical analysis using antibodies recognizing both human COMT and mouse Comt proteins. Consistent with reports of abundant expression of rat Comt in hippocampus (Matsumoto et al, 2003), mouse endogenous Comt expresses highly in hippocampal CA3 pyramidal neurons, cortical neurons, but less in striatum (Figure 2a). As expected, COMT Met and Val proteins displayed the same expression pattern in the humanized mice as the mouse endogenous Comt proteins in wild-type mice. Western blot analyses found comparable expression levels of mouse Comt, human COMT Met, and Val proteins (Figure $2 b$, top panel). To differentiate mouse
Comt from human COMT Met and Val proteins, we used mouse monoclonal antibodies to recognize only mouse Comt proteins in western blot (Figure $2 b$, middle panel). No mouse endogenous Comt proteins were detected in either humanized COMT Met or Val mice. Human COMT Met displayed significantly lower enzymatic activity than either human COMT Val or mouse endogenous Comt proteins (Figure 2c).

\section{Exploratory Behavior}

Because differences in exploratory and anxiety-like behavior are a potential confound for interpretation of many of the behavioral functions described below, we assessed locomotor activity in relatively low stress (behavioral pattern monitor: dark, enclosed chamber) and mild stress environments (open field, light dark box: brightly lit, open areas). In the behavioral pattern monitor, initial use of factor time ( $10 \mathrm{~min}$ blocks) in the ANOVA showed no interaction with gene or sex thus data were analyzed collapsed over the $60 \mathrm{~min}$ session. Both male and female Met/Met and Val/Val mice showed no significant differences in distance travelled, transitions, center time or nose poking behavior (Supplementary Figure 1). Female Met/Met mice reared significantly more than female $\mathrm{Val} / \mathrm{Val}$ mice $($ Sex $\times$ Gene: $\mathrm{F}(1,75)=5.03, P<0.05$; in female mice Gene: $\mathrm{F}(1,35)=7.69, P=0.009)$. Male rearing behavior did not
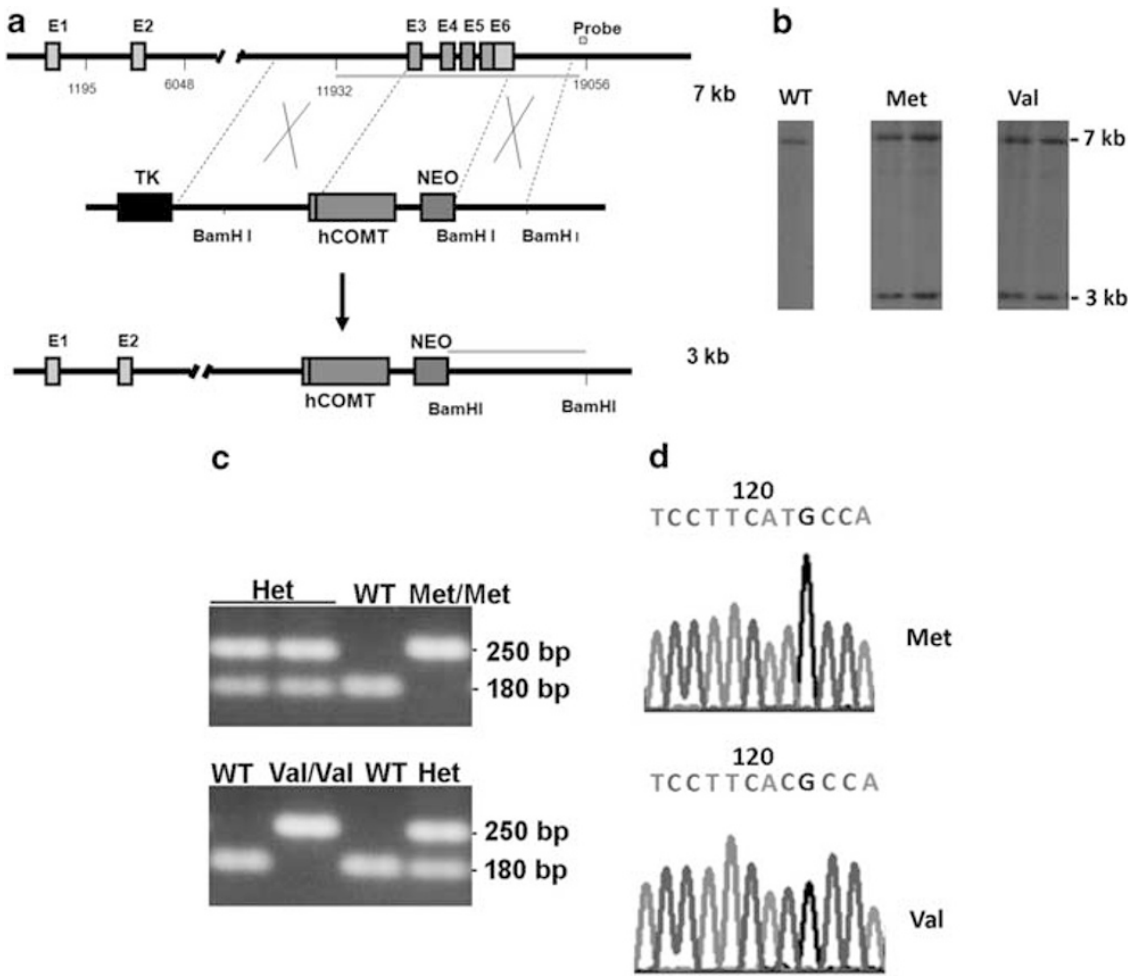

Figure I Generation of humanized mice carrying human COMT Met/Val genes. (a) mouse endogenous Comt gene was replaced with human COMT genes carrying either Met or Val polymorphism in mouse ES cells using gene targeting. The intron I and 2 of the mouse Comt gene are retained to preserve the $5^{\prime}$ flanking regulatory elements. (b) After homologous recombination, recombinant ES colonies were first identified with PCR amplification. The positive colonies were confirmed with southern blot analysis. After digestion with BamH I enzyme, mouse endogenous Comt DNA generated a $7 \mathrm{~kb}$ band, while the targeted human COMT gene produced a $3 \mathrm{~kb}$ band after hybridization with the probe. (c) Germline transmission of the targeted human COMT Met and Val genes in mouse breeding. Heterozygous and homozygous COMT Met and Val mice were genotyped with PCR amplification. (d) human COMT Met and Val RNA were amplified with RT-PCR and confirmed by sequencing. 
a

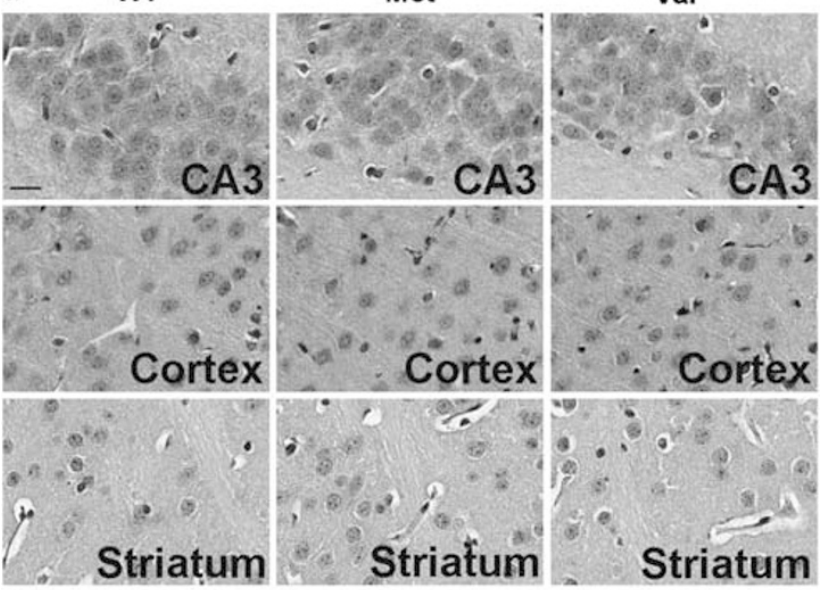

b Striatum Frontal Cortex

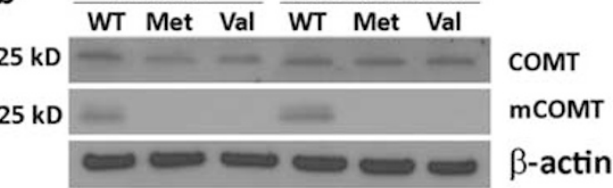

C

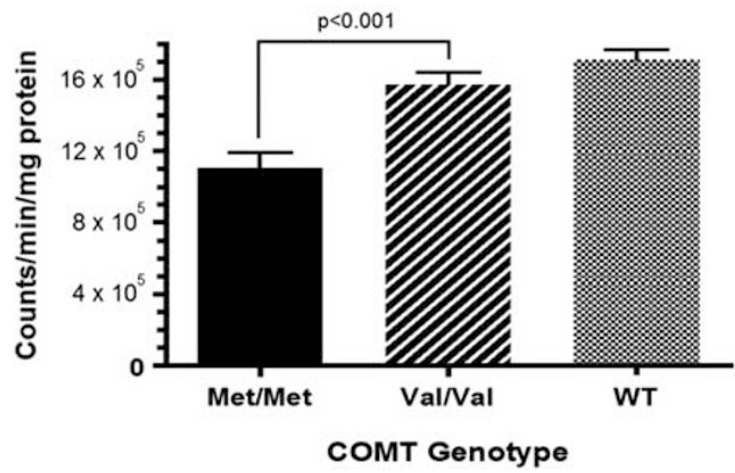

Figure 2 Expression of human COMT Met and $\mathrm{Val}$ genes in the humanized mice. (a) Goat anti-COMT antibody (sc-28II9, Santa Cruz), recognizing both human COMT and mouse Comt proteins, was used to conduct immunohistochemical staining of mouse Comt proteins in wildtype mice and human COMT Met and Val proteins in the homozygous mice. Expression of the Comt and COMT proteins was readily observed in mouse hippocampus, cortex, and striatum. Scale bar, $20 \mu \mathrm{m}$. (b) Western blot analysis confirmed comparable expression of mouse Comt proteins and human COMT Met and Val proteins in both hippocampus and cortex. The top panel western blot was conducted with the goat anti-COMT antibody. The middle panel western blot was conducted with mouse monoclonal anti-mouse Comt (BD Transduction) recognizing only mouse Comt proteins. $50 \mu \mathrm{g}$ proteins of each sample were loaded for electrophoresis. (c) Human COMT activity was measured and compared between Met and $\mathrm{Val}$ isoforms in the brains of the homozygous mice. Wild-type mouse Comt was included for comparison.

differ by genotype. Open field and light-dark box behavior were unaffected by genotype (Supplementary Table 1).

\section{Prepulse inhibition}

PPI was measured in two ways, first by varying the prepulse 'salience' by altering the intensity of the prepulse $(68-77 \mathrm{db})$ and then by varying the interstimulus length (ISI: 25-500 ms) which probes the temporal 'processing' window
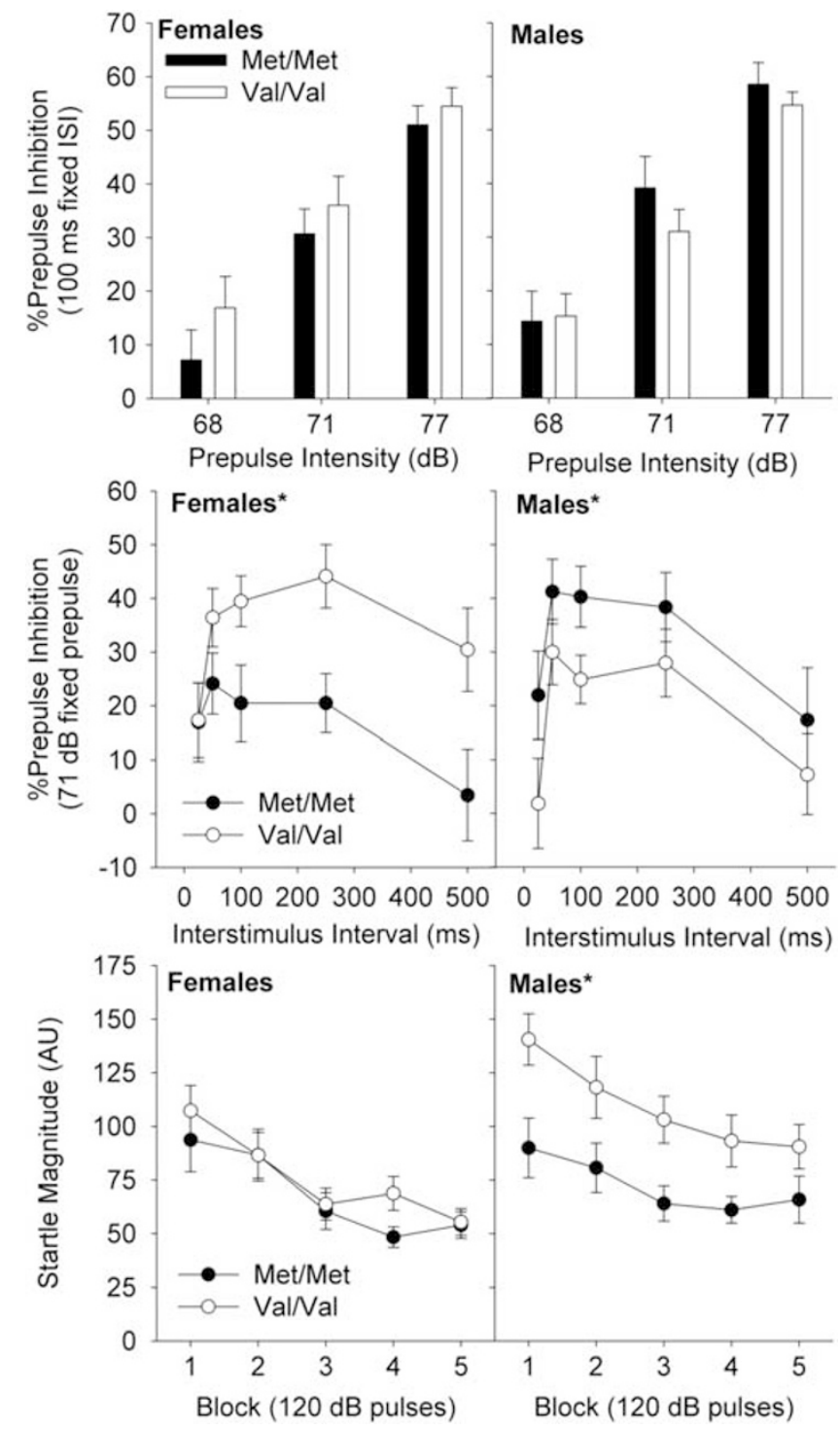

Figure 3 COMT effects on PPI depend upon sex and stimulus parameters. Upper panel: genotype has no effect on sensorimotor gating under conditions of varied prepulse intensity (68-77dB) with fixed interstimulus interval ( $100 \mathrm{~ms}$ prepulse onset-pulse onset). Middle panel: COMT genotype effects on PPI are dependent upon sex when varying interstimulus interval (25-500 ms prepulse-pulse onset) under fixed prepulse intensity conditions $(77 \mathrm{~dB})$. $* P<0.05$ Main effect of Gene, no interaction with interstimulus interval. Lower panel: startle reactivity is reduced in Met/Met male mice compared with Val/Val Male mice $* P<0.05$ main effect of Gene, no interaction with block. See results for detailed description of statistics. $N=17-23 /$ group.

in which the prepulse can influence the startle response (Giakoumaki et al, 2008). In the block with the fixed ISI but varied prepulse intensities, there were no effects of Gene (Figure 3 upper panel) (prepulse intensity: $\mathrm{F}(2,150)=181$, $P<0.0001$; Gene: $\mathrm{F}(1,75)<1)$. However, in the block in which the onset of the prepulse was varied, there was a robust effect of Gene that was dependent upon Sex, with Met/Met female mice showing lower PPI than Val/Val female mice, whereas Met/Met male mice exhibited higher PPI than Val/Val male mice (Figure 3 middle panel) (Sex $\times$ Gene: $\mathrm{F}(1,75)=8.77, \quad P<0.005$, followed by post hoc 
ANOVA in female mice: $\mathrm{F}(1,35)=6.56, P<0.05$ and male mice: $\mathrm{F}(1,38)=4.34, P<0.05)$. There were no effects of Gene on startle threshold (data not shown). Examining startle responding to $120 \mathrm{~dB}$ pulses over the course of the session showed a main effect of Gene and a trend for a Sex $\times$ Gene interaction (Figure 3 lower panel). Post hoc analysis showed the main effect was largely driven by a robust reduction in startle reactivity in male Met/Met mice compared with male Val/Val mice (Gene: $\mathrm{F}(1,75)=6.31, P<0.05$, Sex $\times$ Gene: $\mathrm{F}(1,75)=2.7, P=0.1$, followed by post hoc ANOVA in female mice: Gene: $F(1,35)<1$ and male mice Gene: $\mathrm{F}(1,38)=5.98, P<0.05)$. Because of the reduced startle reactivity in Met/Met mice, there is a possibility that these baseline startle effects may confound PPI differences. To test this question, we reanalyzed PPI during the ISI block with the magnitude of baseline startle reactivity as a covariate (Young et al, 2010). The main effect of Gene was actually strengthened (Gene: $\mathrm{F}(1,37)=8.66, P<0.01$ ) with the covariate of baseline startle included in the model (significant effect of covariate $\mathrm{F}(1,37)=7.31, P<0.05)$.

\section{Working Memory}

In Val158Met mice, working memory was assessed via spontaneous alternation which probes the mouse's ability to remember previous arm visits with proactive interference as trials accumulate. A robust effect of Gene on \%alternation was observed, with both male and female Val/Val mice exhibiting significantly less \%alternation than Met/Met mice (Figure 4, left panel; main effect of Gene: $\mathrm{F}(1,44)=$ 41.6, $P<0.0001)$. There was no main effect or interaction with Sex. Both male and female Met/Met mice exhibited significantly higher alternation compared with chance levels $\left(50 \%, t_{11}=3.29, P<0.01, t_{11}=13.27, P<0.001\right.$, respectively), whereas $\mathrm{Val} / \mathrm{Val}$ mice showed no significant difference from chance. There were no effects of Gene or Sex on time to make a choice (Mean \pm SEM: male mice: $\mathrm{Val} / \mathrm{Val}=17.9 \pm 2.2, \mathrm{Met} / \mathrm{Met}=18.8 \pm 1.5$; female mice $\mathrm{Val} /$ $\mathrm{Val}=19.7 \pm 2.9, \mathrm{Met} / \mathrm{Mt}=16.1 \pm 1.1)$. Although there was

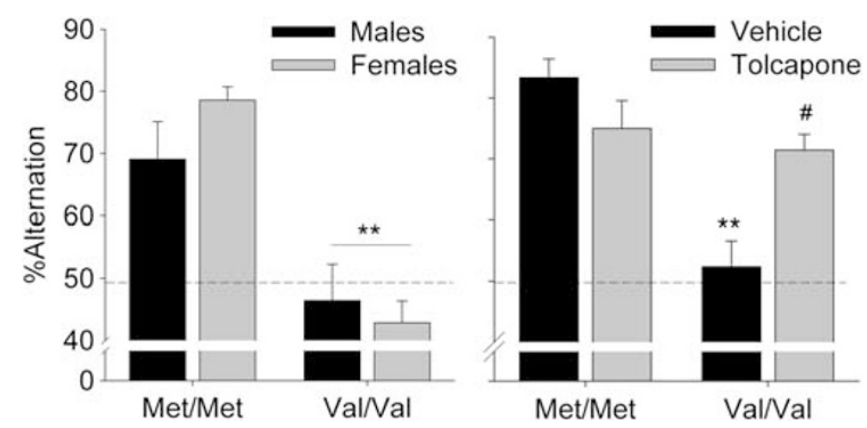

Figure $4 \mathrm{COMT} \mathrm{Val/Val}$ mice exhibit reduced working memory that is significantly improved with tolcapone treatment. Left panel: male and female Met/Met mice exhibit increased \%alternation compared with $\mathrm{Val} / \mathrm{Val}$ mice in a T-maze spontaneous alternation task. ***Main effect of genotype, no interaction with sex. $N=12 /$ group. Right panel: female mice were tested for spontaneous alternation in a within-subject design (I week washout between tests counterbalanced for dose order) after Vehicle and Tolcapone $(20 \mathrm{mg} / \mathrm{kg}, \mathrm{IP})$ treatment. $* * * 0.0 \mathrm{I}$ vs Met $/$ Met Vehicle post hoc $t$-test with alpha correction $(\alpha / 2),{ }^{\#} P<0.00$ I vs $\mathrm{Val} / \mathrm{Val}$ Vehicle post hoc paired test with alpha correction $(\alpha / 2) . N=12$ /group. no interaction with Sex, female mice did appear to exhibit a larger effect size for Gene compared with male mice (Cohen's $D=1$ and 3.6, respectively). Because of the stronger Gene effect observed in female mice, we used this sex to examine the response to Tolcapone administration. Tolcapone treatment significantly increased Val/Val alternation, while showing a trend to reduce alternation in Met/Met mice (Figure 4, right panel; Gene $\times$ Treatment $\mathrm{F}(1,22)=20.56, \quad P<0.0001, P<0.0001$, and $P<0.05$ in respective paired $t$-tests, corrected alpha $=0.025$ ). There were no effects of Tolcapone treatment or Gene on time to make a choice (Mean \pm SEM in seconds: Met/Met vehicle $=15.3 \pm 2.3 ;$ Met $/$ Met Tolcapone $=14.6 \pm 2.3 ; \mathrm{Val} /$ Val vehicle $=17.7 \pm 2.7 ; \mathrm{Val} / \mathrm{Val}$ Tolcapone $=17.6 \pm 2.4)$.

\section{Fear Learning and Extinction}

In humans, fear/anxiety response and extinction performance is linked to the Val158Met polymorphism (Lonsdorf et al, 2009, 2010; Norrholm et al. 2013). To examine if this phenotype is also affected in Val158Met mice, we examined their responses in a pavlovian fear conditioning model. Gene had no effect on acquisition of fear conditioning across either sex (Figure 5, left panel). In the contextual fear test, female mice exhibited a robust increase in freezing for the first $6 \mathrm{~min}$ of the test, and then showed a decline (Figure 5; block: $\mathrm{F}(3,93)=9.19, P<0.001$ ). Female Met/Met mice exhibited less of an increase in freezing across the session compared with female Val/Val mice (Block $\times$ Gene: $\mathrm{F}(3,93)=3.54, P<0.05)$. Male mice exhibited stable freezing responses across the $8 \mathrm{~min}$ session that was not affected by Gene. In the cued fear test ( $24 \mathrm{~h}$ after contextual fear test), female Met/Met mice exhibited increased cued fear recall compared with $\mathrm{Val} / \mathrm{Val}$ mice in the initial two blocks of testing which then disappeared with further extinction training trials $\left({ }^{\star} P<0.05\right.$ Tukey's post hoc test, Block $\times$ Gene: $\mathrm{F}(6,192)=5.69, P<0.05)$. Gene had no effect on male mice, with both groups exhibiting robust fear recall and extinction over the session (Block: $F(9,288)=14.3, P<0.0001$ ). During the extinction recall test $(24 \mathrm{~h}$ after cued recall and extinction training session), female Met/Met mice exhibited significantly higher cued fear in the first block but rapidly reduced freezing to Val/Val levels in subsequent blocks $(P<0.05$ Tukey's post hoc test after Cue $\times$ Block $\mathrm{F}(3,93)=4.7, P<0.05)$. Male mice showed no effect of Gene on extinction recall.

\section{DISCUSSION}

Here we describe the first characterization of mice 'humanized' for the human COMT gene with the Val158Met polymorphism. These mice reproduced normally and showed no overt differences, with overall behavioral responses within the expected range reported for wild-type C57Bl6J mice in these tests (Bontempi et al. 2003; Gresack et al 2010; Gresack and Risbrough, 2011). The enzymatic activity of COMT extracted from cortex was comparable with the expected $\sim 30 \%$ reduction in enzymatic efficacy in Met/Met gene carriers vs Val/Val (Chen et al, 2004). Behaviorally these mice displayed relatively subtle behavioral alterations, with strongest genotype effects in female mice compared with male mice. In male mice, Met/Met 
FEMALES
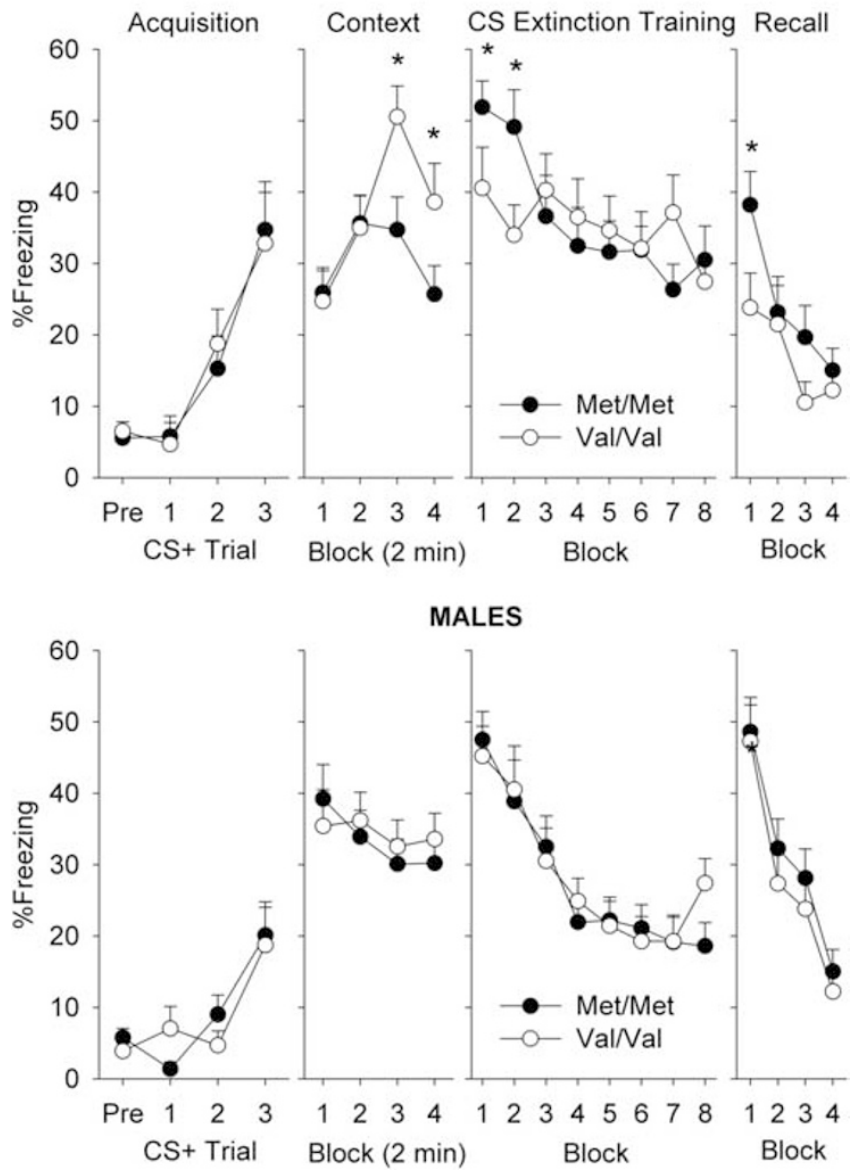

Figure 5 Female COMT Met/Met mice exhibit reduced contextual fear, increased cued fear, and reduced extinction recall. Fear learning and extinction was tested over a four consecutive-day battery in female (top) and male (bottom) COMT Val I 58Met mice. Fear acquisition to three toneshock pairings occurred on day I, contextual fear to the acquisition context ( $8 \mathrm{~min}$, Block $=2 \mathrm{~min}$ ) was measured on day 2 , cued fear recall and extinction training occurred on day 3 (Block = four tone trials), and extinction recall (Block $=$ four tone trials) occurred on day 4. $* P<0.05$ vs $\mathrm{Val} / \mathrm{Val}$ at respective time point, Tukey's test. $N=16-18 /$ group.

genotype conferred reduced startle reactivity and increased PPI, while exploratory behavior and fear learning remained similar across the genotypes. In contrast, female mice with Met/Met genotype exhibited reduced PPI, increased exploration as measured by rearing behavior, and increased cued fear with reduced extinction recall. Both sexes showed robust effects of Val158Met on spatial working memory, with Met/Met mice showing significantly higher spatial working memory compared with $\mathrm{Val} / \mathrm{Val}$. Tolcapone treatment effects on alternation are highly dependent on genotype, with tolcapone-treated $\mathrm{Val} / \mathrm{Val}$ mice showing significant improvements while tolcapone reduced the alternation in Met/Met mice. These data support the hypothesis that the Val158Met polymorphism affects cognitive and emotional processes, with strongest effects on spontaneous alternation. Some of the phenotypes (sensorimotor gating in male mice; working memory, fear extinction in female mice) and treatment effects (differential tolcapone response) mimic similar results described for these genotypes in human populations, supporting the predictive validity of this model for at least some COMT Val158Met functions in humans.

In the present study, we observed a parameter- and sexspecific effect of the Val158Met polymorphism on sensorimotor gating in mice. Male Val/Val mice exhibited reduced PPI under conditions of varied interstimulus intervals, but this effect did not reach significance when we fixed the interstimulus at $100 \mathrm{~ms}$ and varied prepulse intensity. In both healthy male mice and male mice with schizophrenia, the Val158Met polymorphism has been shown to modulate PPI in a similar direction using similar parameters (varied interstimulus intervals) (Giakoumaki et al, 2008; Quednow et al, 2008; Roussos et al, 2008). In women however, Val158Met had no association with PPI performance (Montag et al, 2008; Quednow et al, 2009). Conversely, we observed significant decreases in PPI in female Met/Met mice compared with Val/Val mice under varied interstimulus interval conditions. Previous studies have suggested a strong sexually dimorphic effect of COMT (Papaleo et al, 2012; Laatikainen et al, 2013; for review see Tunbridge and Harrison, 2011) on brain and behavior, as well as 'protective' effects of estrogen receptor activation from dopamine agonist-induced PPI deficits (Gogos et al, 2010). Estrogen modulates dopamine transporter and receptor levels in the striatum, an area critical for dopamine modulation of PPI (Chavez et al, 2010). Thus, it is plausible that estrogen signaling in female mice modifies dopamine signaling and subsequent PPI phenotypes in COMTVal158Met mice. Further characterization of estrogen effects on catecholamine signaling in this model is warranted to explore this hypothesis. Comt-deficient mice and mice with transgenic expression of the human COMT-Val do not show alterations in PPI (Gogos et al, 1998b; Papaleo et al, 2008b); however, these studies did not vary interstimulus interval as was done in the present study. It is not clear why varying interstimulus intervals would better 'unmask' a difference in PPI performance compared with varying the stimulus intensity. One speculation is that temporal vs intensity challenges may probe differential attributes of this 'prefiltering' system. PPI is characterized by a well-defined temporal window, reflecting the prepulse processing period, during which the prepulse presentation inhibits startle responses (30-300 ms). In humans, varying the interstimulus intervals between 30 and $300 \mathrm{~ms}$ probes both 'preconscious' and conscious filtering mechanisms ( $<60$ and $>60 \mathrm{~ms}$, respectively), while altering stimulus intensity may only challenge salience processing (Swerdlow et al, 2008). There is some support for differential signaling mechanisms to modulate this temporal window; in rats, dopamine D1 receptor signaling may have a greater role in PPI at short interstimulus intervals with D2 receptor signaling having a role at longer intervals (Swerdlow et al, 2004). Thus it is possible that the varied interstimulus intervals probe PPI-relevant circuitry or pathways that are more strongly modulated by COMT.

In humans, healthy carriers of the Met allele have increased brain activation in the frontal cortex, amygdala, and hippocampus in response to emotional or painful stimuli compared with Val carriers, suggesting higher sensitivity to aversive stimuli (Smolka et al, 2005; Drabant et al, 2006). The COMT Met allele has also been associated with poorer fear extinction than Val carriers in healthy 
controls (Lonsdorf et al, 2009; Norrholm et al, 2013). These studies in humans did not detect an effect of sex on Val158Met associations with these measures, however these studies were not powered to do so. Here, we observed sexspecific effects of COMTVal158Met on fear learning processes. Female but not male Met/Met mice exhibited a number of differences in fear learning and extinction compared with $\mathrm{Val} / \mathrm{Val}$ mice. Compared with $\mathrm{Val} / \mathrm{Val}$ mice, Met/Met mice exhibited reduced freezing to a context previously associated with shock, while exhibiting greater freezing responses to discrete conditioned fear cues. With repeated CS presentations, Met/Met mice extinguished to similar levels of freezing as Val/Val mice, however $24 \mathrm{~h}$ later their initial extinction recall was reduced. The fear learning phenotype is also relatively specific, as Val158Met mice exhibited no change in anxiety-like behaviors as measured by open field or light dark box tests. Taken together, these data suggest that female Val158Met mice may be a useful model to dissect the role of COMT in fear learning/ extinction and fear disorders such as PTSD. Indeed, the Met allele has recently been suggested to be a vulnerability factor for PTSD, a disorder characterized by increased fear conditioning and disruptions in extinction (Kolassa et al, 2010; Boscarino et al, 2011; Norrholm et al, 2011; Valente et al, 2011).

The most robust effect of Val158Met observed in these studies was on spatial working memory as assessed by spontaneous alternation. The spontaneous alternation test requires functional prelimbic cortex and hippocampus and appears to require an optimum level of catecholamine signaling for maximal alternation (for review, see Lalonde, 2002). In the present studies, both male and female Met/Met mice showed greater alternation than $\mathrm{Val} / \mathrm{Val}$ mice, indeed $\mathrm{Val} / \mathrm{Val}$ mice performed at chance levels. These data are in line with previous studies showing mCOMT Val-tg mice exhibit reduced working memory compared with COMT knockout mice (Papaleo et al, 2012). Importantly, treatment with the COMT inhibitor tolcapone significantly reversed the Met and Val phenotypes, improving Val/Val mice while reducing alternation in Met/Met mice. These data are similar to the higher performance of Met carriers compared with Val carriers in some working memory tasks in humans (Barnett et al, 2007; Diaz-Asper et al, 2008; but see Barnett et $a l, 2008)$, and the reversal of these phenotypes by tolcapone administration (Giakoumaki et al, 2008; Farrell et al, 2012). These data support the hypothesis that there is an 'inverted U-shaped' dose response for catecholamine signaling modulation of cognitive functions such as working memory and/or behavioral flexibility (Bilder et al, 2004; Rolls et al, 2008; Gamo and Arnsten, 2011; Sheynikhovich et al, 2013). It remains to be tested what putative mechanism (eg, increased and decreased D1 signaling in Met/Met and Val/Val mice, respectively; (Bilder et al, 2004)) and neural circuitry (eg, prelimbic cortex vs hippocampus) underlies the Val158Met effect on alternation.

In conclusion, we have established two knock-in human COMTVal158Met mouse lines that mimic at least some of the functional differences described in $\mathrm{Val}$ and Met carriers in humans, including Met/Met phenotypes of increased working memory (both sexes), increased PPI (male mice) and reduced extinction recall (female mice). These mice may be an ideal model in which to examine the mechanism of Val158Met polymorphism effects on executive function and cognitive processes relevant to a number of neuropsychiatric disorders including schizophrenia and PTSD. These mice may also be particularly useful for screening novel pharmacotherapeutics for enhancing catecholamine signaling in Val carriers, as well as dissecting the recently described role of COMTVal158Met on forebrain development (Raznahan et al, 2011) and epistatic gene interactions (Papeleo et al, 2013).

\section{FUNDING AND DISCLOSURE}

The authors declare no conflict of interests.

\section{ACKNOWLEDGEMENTS}

The present manuscript reports original research which has not been previously published and has not been submitted for publication elsewhere. These studies were funded by NIMH083499 and UL RR031980 pilot grant to VBR and XZ, MH073991 to XZ, NIMH042228, VA Mental Illness Research and Clinical Core, Center of Excellence for Stress and Mental Health. We would like to thank Alan Turken, Maya Gross, Mike Schuchbauer, and Minjung Kim for their technical assistance.

\section{REFERENCES}

Barnett JH, Jones PB, Robbins TW, Muller U (2007). Effects of the catechol-O-methyltransferase Val158Met polymorphism on executive function: a meta-analysis of the Wisconsin Card Sort Test in schizophrenia and healthy controls. Mol Psychiatry 12: 502.

Barnett JH, Scoriels L, Munafã2 MR (2008). Meta-analysis of the cognitive effects of the Catechol-O-Methyltransferase Gene Val158/108Met polymorphism. Biol Psychiatry 64: 137-144.

Bilder RM, Volavka J, Lachman HM, Grace AA (2004). The catechol-O-methyltransferase polymorphism: relations to the tonic-phasic dopamine hypothesis and neuropsychiatric phenotypes. Neuropsychopharmacology 29: 1943-1961.

Bontempi B, Whelan KT, Risbrough VB, Lloyd GK, Menzaghi F (2003). Cognitive enhancing properties and tolerability of cholinergic agents in mice: a comparative study of nicotine, donepezil, and SIB-1553A, a subtype-selective ligand for nicotinic acetylcholine receptors. Neuropsychopharmacology 28: 1235-1246.

Boscarino JA, Erlich PM, Hoffman SN, Rukstalis M, Stewart WF (2011). Association of FKBP5, COMT and CHRNA5 polymorphisms with PTSD among outpatients at risk for PTSD. Psychiatry Res 188: 173-174.

Buckert M, Kudielka BM, Reuter M, Fiebach CJ (2012). The COMT Val158Met polymorphism modulates working memory performance under acute stress. Psychoneuroendocrinology 37: 1810-1821.

Caldu X, Vendrell P, Bartres-Faz D, Clemente I, Bargallo N, Jurado MA et al (2007). Impact of the COMT Val108/158 Met and DAT genotypes on prefrontal function in healthy subjects. Neuroimage 37: 1437-1444.

Chavez C, Hollaus M, Scarr E, Pavey G, Gogos A, van den Buuse M (2010). The effect of estrogen on dopamine and serotonin receptor and transporter levels in the brain: an autoradiography study. Brain Res 1321: 51-59.

Chen CY, Lu RB, Yeh YW, Shih MC, Huang SY (2011a). Association study of catechol-O-methyltransferase gene polymorphisms with schizophrenia and psychopathological symptoms in Han Chinese. Genes Brain Behav 10: 316-324. 
Chen J, Lipska BK, Halim N, Ma QD, Matsumoto M, Melhem S et al (2004). Functional analysis of genetic variation in catechol-Omethyltransferase (COMT): effects on mRNA, protein, and enzyme activity in postmortem human brain. Am J Hum Genet 75: 807-821.

Chen J, Song J, Yuan P, Tian Q, Ji Y, Ren-Patterson R et al (2011b). Orientation and cellular distribution of membrane-bound catechol-O-methyltransferase in cortical neurons: implications for drug development. J Biol Chem 286: 34752-34760.

Diaz-Asper CM, Goldberg TE, Kolachana BS, Straub RE, Egan MF, Weinberger DR (2008). Genetic variation in catechol-O-methyltransferase: effects on working memory in schizophrenic patients, their siblings, and healthy controls. Biol Psychiatry 63: 72-79.

Drabant EM, Hariri AR, Meyer-Lindenberg A, Munoz KE, Mattay VS, Kolachana BS et al (2006). Catechol O-methyltransferase val158met genotype and neural mechanisms related to affective arousal and regulation. Arch Gen Psychiatry 63: 1396-1406.

Egan MF, Goldberg TE, Kolachana BS, Callicott JH, Mazzanti CM, Straub RE et al (2001). Effect of COMT Val108/158 Met genotype on frontal lobe function and risk for schizophrenia. Proc Natl Acad Sci USA 98: 6917-6922.

Fan JB, Zhang CS, Gu NF, Li XW, Sun WW, Wang HY et al (2005). Catechol-O-methyltransferase gene Val/Met functional polymorphism and risk of schizophrenia: a large-scale association study plus meta-analysis. Biol Psychiatry 57: 139-144.

Farrell SM, Tunbridge EM, Braeutigam S, Harrison PJ (2012). COMT $\operatorname{Val}(158)$ Met genotype determines the direction of cognitive effects produced by catechol-O-methyltransferase inhibition. Biol Psychiatry 71: 538-544.

Gamo NJ, Arnsten AF (2011). Molecular modulation of prefrontal cortex: rational development of treatments for psychiatric disorders. Behav Neurosci 125: 282-296.

Geyer MA, Russo PV, Masten VL (1986). Multivariate assessment of locomotor behavior: pharmacological and behavioral analyses. Pharmacol Biochem Behav 25: 277-288.

Giakoumaki SG, Roussos P, Bitsios P (2008). Improvement of prepulse inhibition and executive function by the COMT inhibitor tolcapone depends on COMT Val158Met polymorphism. Neuropsychopharmacology 33: 3058-3068.

Glatt SJ, Faraone SV, Tsuang MT (2003). Association between a functional catechol O-methyltransferase gene polymorphism and schizophrenia: meta-analysis of case-control and familybased studies. Am J Psychiatry 160: 469-476.

Gogos A, Kwek P, Chavez C, van den Buuse M (2010). Estrogen treatment blocks 8-hydroxy-2-dipropylaminotetralin- and apomorphine-induced disruptions of prepulse inhibition: involvement of dopamine D1 or D2 or serotonin 5-HT1A, 5-HT2A, or 5HT7 receptors. J Pharmacol Exp Ther 333: 218-227.

Gogos JA, Morgan M, Luine V, Santha M, Ogawa S, Pfaff D et al (1998a). Catechol-O-methyltransferase-deficient mice exhibit sexually dimorphic changes in catecholamine levels and behavior. Proc Natl Acad Sci U S A 95: 9991-9996.

Gogos JA, Morgan M, Luine V, Santha M, Ogawa S, Pfaff D et al (1998b). Catechol-O-methyltransferase-deficient mice exhibit sexually dimorphic changes in catecholamine levels and behavior. PNAS 95: 9991-9996.

Gothelf D, Eliez S, Thompson T, Hinard C, Penniman L, Feinstein $\mathrm{C}$ et al (2005). COMT genotype predicts longitudinal cognitive decline and psychosis in 22q11.2 deletion syndrome. Nat Neurosci 8: 1500.

Gresack JE, Risbrough VB (2011). Corticotropin-releasing factor and noradrenergic signalling exert reciprocal control over startle reactivity. Int J Neuropsychopharmacol 14: 1179-1194.

Gresack JE, Risbrough VB, Scott CN, Coste S, Stenzel-Poore M, Geyer MA et al (2010). Isolation rearing-induced deficits in contextual fear learning do not require CRF2 receptors. Behav Brain Res 209: 80-84.
Huotari M, Gogos JA, Karayiorgou M, Koponen O, Forsberg M, Raasmaja A et al (2002). Brain catecholamine metabolism in catechol-O-methyltransferase (COMT)-deficient mice. Eur J Neurosci 15: 246-256.

Kim M, Soontornniyomkij V, Ji B, Zhou X (2012). System-wide immunohistochemical analysis of protein co-localization. PLoS One 7: e32043.

Kolassa I-T, Kolassa S, Ertl V, Papassotiropoulos A, De Quervain DJF (2010). The risk of posttraumatic stress disorder after trauma depends on traumatic load and the catechol-O-methyltransferase Val158Met polymorphism. Biol Psychiatry 67: 304-308.

Laatikainen LM, Sharp T, Harrison PJ, Tunbridge EM (2013). Sexually dimorphic effects of catechol-O-methyltransferase (COMT) inhibition on dopamine metabolism in multiple brain regions. PLoS One 8: e61839.

Lachman HM, Papolos DF, Saito T, Yu YM, Szumlanski CL, Weinshilboum RM (1996). Human catechol-O-methyltransferase pharmacogenetics: description of a functional polymorphism and its potential application to neuropsychiatric disorders. Pharmacogenetics 6: 243-250.

Lalonde R (2002). The neurobiological basis of spontaneous alternation. Neurosci Biobehav Rev 26: 91-104.

Lonsdorf TB, Ruck C, Bergstrom J, Andersson G, Ohman A, Lindefors $\mathrm{N}$ et al (2010). The COMTval158met polymorphism is associated with symptom relief during exposure-based cognitive-behavioral treatment in panic disorder. BMC Psychiatry 10: 99.

Lonsdorf TB, Weike AI, Nikamo P, Schalling M, Hamm AO, Ohman A (2009). Genetic gating of human fear learning and extinction: possible implications for gene-environment interaction in anxiety disorder. Psychol Sci 20: 198-206.

Matsumoto M, Weickert CS, Akil M, Lipska BK, Hyde TM, Herman MM et al (2003). Catechol O-methyltransferase mRNA expression in human and rat brain: evidence for a role in cortical neuronal function. Neuroscience 116: 127-137.

Montag C, Hartmann P, Merz M, Burk C, Reuter M (2008). D2 receptor density and prepulse inhibition in humans: negative findings from a molecular genetic approach. Behav Brain Res 187: 428-432.

Murphy KC, Jones LA, Owen MJ (1999a). High rates of schizophrenia in adults with velo-cardio-facial syndrome. Arch Gen Psychiatry 56: 940-945.

Murphy KC, Jones LA, Owen MJ (1999b). High rates of schizophrenia in adults with velo-cardio-facial syndrome. Arch Gen Psychiatry 56: 940-945.

Nieratschker V, Frank J, Muhleisen TW, Strohmaier J, Wendland JR, Schumacher J et al (2010). The catechol-O-methyl transferase (COMT) gene and its potential association with schizophrenia: findings from a large German case-control and family-based sample. Schizophr Res 122: 24-30.

Norrholm SD, Jovanovic T, Olin IW, Sands LA, Karapanou I, Bradley B et al (2011). Fear extinction in traumatized civilians with posttraumatic stress disorder: relation to symptom severity. Biol Psychiatry 69: 556-563.

Norrholm SD, Jovanovic T, Smith A, Binder EB, Klengel T, Conneely $\mathrm{K}$ et al (2013). Differential genetic and epigenetic regulation of catechol-O-methyl-transferase (COMT) is associated with impaired fear inhibition in posttraumatic stress disorder. Front Behav Neurosci 7: 1-10.

Orsini CA, Maren S (2012). Neural and cellular mechanisms of fear and extinction memory formation. Neurosci Biobehav Rev 36: 1773-1802.

Palmatier MA, Kang AM, Kidd KK (1999). Global variation in the frequencies of functionally different catechol-O-methyltransferase alleles. Biol Psychiatry 46: 557-567.

Papaleo F, Crawley JN, Song J, Lipska BK, Pickel J, Weinberger DR et al (2008a). Genetic dissection of the role of catechol-Omethyltransferase in cognition and stress reactivity in mice. J Neurosci 28: 8709-8723. 
Papaleo F, Crawley JN, Song J, Lipska BK, Pickel J, Weinberger DR et al (2008b). Genetic dissection of the role of catechol-Omethyltransferase in cognition and stress reactivity in mice. J Neurosci 28: 8709-8723.

Papaleo F, Erickson L, Liu G, Chen J, Weinberger DR (2012). Effects of sex and COMT genotype on environmentally modulated cognitive control in mice. Proc Natl Acad Sci 109: 20160-20165.

Papaleo F, Burdick MC, Callicott JH, Weinberger DR (2013). Epistatic interaction between COMT and DTNBP1 modulates prefrontal function in mice and in humans. Mol Psychiatry 19: 311-316.

Quednow BB, Schmechtig A, Ettinger U, Petrovsky N, Collier DA, Vollenweider FX et al (2009). Sensorimotor gating depends on polymorphisms of the serotonin-2A receptor and catechol-Omethyltransferase, but not on neuregulin-1 Arg38Gln genotype: a replication study. Biol Psychiatry 66: 614-620.

Quednow BB, Wagner M, Mossner R, Maier W, Kuhn KU (2008). Sensorimotor gating of schizophrenia patients depends on catechol O-methyltransferase Val158Met polymorphism. Schizophr Bull 36: 341-346.

Raznahan A, Greenstein D, Lee Y, Long R, Clasen L, Gochman P et al (2011). Catechol-o-methyl transferase (COMT) val158met polymorphism and adolescent cortical development in patients with childhood-onset schizophrenia, their non-psychotic siblings, and healthy controls. Neuroimage 57: 1517-1523.

Risbrough VB, Masten VL, Caldwell S, Paulus MP, Low MJ, Geyer MA (2006). Differential contributions of dopamine D1, D2, and D3 receptors to MDMA-induced effects on locomotor behavior patterns in mice. Neuropsychopharmacology 31: 2349-2358.

Rolls ET, Loh M, Deco G, Winterer G (2008). Computational models of schizophrenia and dopamine modulation in the prefrontal cortex. Nat Rev Neurosci 9: 696-709.

Roussos P, Giakoumaki SG, Rogdaki M, Pavlakis S, Frangou S, Bitsios P (2008). Prepulse inhibition of the startle reflex depends on the catechol O-methyltransferase Val158Met gene polymorphism. Psychol Med 38: 1651-1658.

Sheynikhovich D, Otani S, Arleo A (2013). Dopaminergic control of long-term depression/long-term potentiation threshold in prefrontal cortex. The Journal of Neuroscience 33: 13914-13926.

Smolka MN, Schumann G, Wrase J, Grusser SM, Flor H, Mann K et al (2005). Catechol-O-methyltransferase val158met genotype affects processing of emotional stimuli in the amygdala and prefrontal cortex. J Neurosci 25: 836-842.

Swerdlow NR, Geyer MA, Braff DL (2001). Neural circuit regulation of prepulse inhibition of startle in the rat: current knowledge and future challenges. Psychopharmacology (Berl) 156: $194-215$.
Swerdlow NR, Shoemaker JM, Auerbach PP, Pitcher L, Goins J, Platten A (2004). Heritable differences in the dopaminergic regulation of sensorimotor gatingII. Temporal, pharmacologic and generational analyses of apomorphine effects on prepulse inhibition. Psychopharmacology (Berl) 174: 452-462.

Swerdlow NR, Weber M, Qu Y, Light GA, Braff DL (2008). Realistic expectations of prepulse inhibition in translational models for schizophrenia research. Psychopharmacology (Berl) 199: 331-388.

Toth M, Gresack JE, Bangasser DA, Plona Z, Valentino RJ, Flandreau EI et al (2014). Forebrain-specific CRF over-production during development is sufficient to induce enduring anxiety and startle abnormalities in adult mice. Neuropsychopharmacology.

Tsao D, Wieskopf JS, Rashid N, Sorge RE, Redler RL, Segall SK et al (2012). Serotonin-induced hypersensitivity via inhibition of catechol O-methyltransferase activity. Mol Pain 8: 25.

Tunbridge EM, Bannerman DM, Sharp T, Harrison PJ (2004). Catechol-o-methyltransferase inhibition improves set-shifting performance and elevates stimulated dopamine release in the rat prefrontal cortex. J Neurosci 24: 5331-5335.

Tunbridge EM, Harrison PJ (2011). Importance of the COMT gene for sex differences in brain function and predisposition to psychiatric disorders. Curr Top Behav Neurosci 8: 119-140.

Tunbridge EM, Harrison PJ, Weinberger DR (2006). Catechol-omethyltransferase, cognition, and psychosis: Val158Met and beyond. Biol Psychiatry 60: 141-151.

Valente No, Vallada H, Cordeiro Q, Bressan R, Andreoli S, Mari J et al (2011). Catechol-O-methyltransferase (COMT) val158met polymorphism as a risk factor for PTSD after urban violence. J Mol Neurosci 43: 516-523.

Wang Y, Li J, Chen C, Chen C, Zhu B, Moysis RK et al (2013). COMT rs4680 Met is not always the 'smart allele': Val allele is associated with better working memory and larger hippocampal volume in healthy Chinese. Genes Brain Behav 12: 323-329.

Williams HJ, Glaser B, Williams NM, Norton N, Zammit S, MacGregor S et al (2005). No association between schizophrenia and polymorphisms in COMT in two large samples. Am J Psychiatry 162: 1736-1738.

Witte AV, Floel A (2012). Effects of COMT polymorphisms on brain function and behavior in health and disease. Brain Res Bull 88: $418-428$.

Young JW, Wallace CK, Geyer MA, Risbrough VB (2010). Ageassociated improvements in cross-modal prepulse inhibition in mice. Behav Neurosci 124: 133-140.

Zhou X, Benson KF, Ashar HR, Chada K (1995). Mutation responsible for the mouse pygmy phenotype in the developmentally regulated factor HMGI-C. Nature 376: 771-774.

Supplementary Information accompanies the paper on the Neuropsychopharmacology website (http://www.nature.com/npp) 